\title{
PREVALENCIA Y CARACTERIZACIÓN MOLECULAR DE ESCHERICHIA COLI Y SALMONELLA SPP. EN GALLINAS DE GUINEA (NUMIDA MELEAGRIS) EN DOS RANCHOS DE CHIAPAS, MÉXICO
}

\author{
PREVALENCE AND MOLECULAR CHARACTERIZATION OF \\ ESCHERICHIA COLI AND SALMONELLA SPP. IN GUINEA FOWLS \\ (NUMIDA MELEAGRIS) IN TWO RANCHES OF CHIAPAS, MEXICO
}

Perla Alejandra Flores Alfonso perla.flores03@unach.mx

\section{Paula Mendoza Nazar}

Benigno Ruíz Sesma

Gerardo Uriel Bautista Trujillo

Néstor Alonso López Ochoa

Facultad de Medicina Veterinaria y Zootecnia

Universidad Autónoma de Chiapas, México
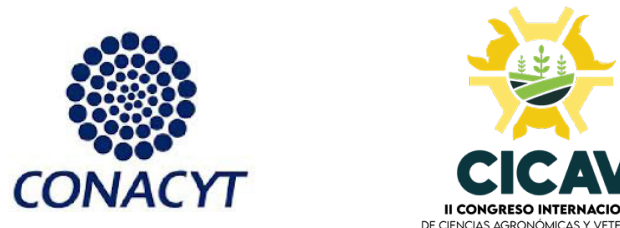
Para citar este artículo:

Flores Alfonso, P. A., Mendoza Nazar, P., Ruíz Sesma, B., Bautista Trujillo, G. U., \& López Ochoa, N. A. (2021). Prevalencia y caracterización molecular de Escherichia coli y Salmonella spp. En gallinas de guinea (Numida meleagris) en dos ranchos de Chiapas, México. ESPACIO I+D, INNOVACIÓN MÁS DESARROLLO, 10(26). https://doi.org/10.31644/ IMASD.26.2021.a08

\section{RESUMEN}

El objetivo del estudio es evaluar la prevalencia y caracterizar molecularmente los aislamientos de Escherichia coli y Salmonella spp. en gallinas de Guinea (Numida meleagris) en dos ranchos de los municipios de Villaflores y La Trinitaria, Chiapas, México. Se muestrearon aleatoriamente un total de 23 guineas, de las cuales se tomaron muestras cloacales para la identificación bacteriana mediante medios selectivos, mientras que para la caracterización molecular se analizó el gen rfbO157 (productor de toxina Shiga). El análisis de datos se realizó mediante prevalencia puntual. Los resultados mostraron que no se encontró presencia de Salmonella spp. ni de Escherichia coli en las guineas del rancho de La Trinitaria. En cuanto a las guineas muestreadas en el rancho de Villaflores, tampoco se encontró presencia de Salmonella spp., sin embargo, se encontró una prevalencia del 95\% de Escherichia coli. La caracterización molecular del 10\% de las muestras de Escherichia coli permitió identificar al serotipo O157:H7 (productor de toxina Shiga). No se encontró prevalencia de Salmonella spp. en guineas; sin embargo, el estudio demuestra que las gallinas de guinea son portadoras de Escherichia coli $\mathrm{O} 157: \mathrm{H} 7$, por lo que es preciso seguir con estudios del impacto del serotipo en la sanidad animal, así como en la salud pública.

\section{Palabras clave}

Cepa enterohemorrágica; Salud pública; Sanidad animal. 


\section{- Abstract-}

The objective of the study was to evaluate the prevalence and molecularly characterize the isolates of Escherichia coli and Salmonella spp. in Guinea fowl (Numida meleagris) in two ranches in the municipalities of Villaflores and La Trinitaria, Chiapas, Mexico. A total of 23 guineas were randomly sampled, from which cloacal samples were taken for bacterial identification using selective media, while the $r f b \mathrm{O}_{157}$ gene (producer of Shiga toxin) was analyzed for molecular characterization. Data analysis was carried out using point prevalence. The results showed that no presence of Salmonella spp. nor of Escherichia coli in the guineas of the La Trinitaria ranch. Regarding the guineas sampled in the Villaflores ranch, no presence of Salmonella spp. Was found, however, a 95\% prevalence of Escherichia coli was found. The molecular characterization of $10 \%$ of the Escherichia coli samples allowed the identification of the serotype O157: H7 (producer of Shiga toxin). No prevalence of Salmonella spp. in guineas; however, the study shows that guinea fowl are carriers of Escherichia coli O157: H7, so it's necessary to continue with studies of the impact of the serotype on animal health, as well as on public health.

\section{Keywords}

Enterohemorrhagic strain; Public health; Animal health. 
L as aves de corral representan una de las principales fuentes de obtención de proteína de origen animal, por esta razón es común encontrar distintas aves domésticas bajo condiciones de traspatio, donde se observan gallinas (Gallus gallus domesticus) y guajolotes (Meleagris gallopavo) principalmente, además de patos (Anas platyrhynchos domesticus), gansos (Anser anser) y gallinas de Guinea (Numida meleagris) (Zaldívar-Pedroso, 2007).

En México, las guineas como especie exótica ocupan un área aproximada de 5,648 ha. (SEMARNAT, 2000), siendo reportadas principalmente en unidades de manejo para la conservación de vida silvestre (UMAs) de Coahuila, Hidalgo y Nuevo León (Goméz-de Silva, et al., 2005).

En la actualidad, la gallina de Guinea ha tomado preferencia en el gusto de las personas para su crianza, ya sea como ave de ornato o productora de carne y/o huevo debido a su rusticidad y el poco manejo. Esta ave tiene su origen en el centro y este africano, y aunque ya era conocida por griegos y romanos, sólo ha sido utilizada recientemente para la producción de carne (Zaldívar-Pedroso, 2007). Entre las ventajas que ofrece la producción de gallinas de Guinea se encuentra su rusticidad y buena adaptación a condiciones adversas, cualidades que la convierten en una especie avícola efectiva y novedosa para los productores de traspatio (Gómez-de Silva, et al., 2005; Salgado, et al., 2011), aunque la información acerca de esta especie en cuanto a la producción es escasa, se conoce que es mantenida en algunas comunidades del país (Camas-Robles, et al., 2017).

Sin embargo, algunas enfermedades originadas por bacterias afectan directamente a las aves, provocando una baja considerable respecto a la producción. La familia Enterobacteriaceae es la más grande y heterogénea de bacilos Gramnegativos con importancia en la salud humana y animal (AraujoGuerra, et al., 2019). Dentro de las enfermedades bacterianas más comunes se encuentran Salmonella spp. y Escherichia coli, las cuales afectan el tracto intestinal del ave, provocando su muerte; adicionalmente, algunos serotipos bacterianos pueden llegar al consumidor a través de la carne o los huevos, generando un impacto negativo en la seguridad e inocuidad alimentaria (Leotta, et al., 2005; Rincón-Acero, et al., 2011; Araujo-Guerra, et al., 2019).

Respecto a Escherichia coli, muchos serotipos han sido asociados con el síndrome urémico hemolítico en humanos (Ochoa, et al., 2004), siendo el serotipo O157:H7 su principal causante. Por otra parte, las infecciones por Salmonella spp. se relacionan con enfermedades transmitidas por alimentos contaminados (Rincón-Acero, et al., 2011) como la carne, que resultan peligrosos cuando son mantenidos bajo circunstancias que favorecen su multiplicación, situación que representa un grave problema de salud pública (Bello-Pérez, et al., 1990; Mussaret, et al., 2006).

Si bien la crianza de gallinas de Guinea representa una alternativa eficiente para la producción de alimentos a pequeña escala, es importante 
realizar estudios para identificar a los microorganismos que ponen en riesgo la salud tanto del animal así como del consumidor. Por tanto, el objetivo del estudio fue evaluar la prevalencia y caracterizar molecularmente los aislamientos de Escherichia coli y Salmonella spp. en gallinas de Guinea (Numida meleagris) en dos ranchos de los municipios de Villaflores y La Trinitaria, Chiapas, México.

\section{MATERIALES Y MÉTODOS}

El presente estudio se realizó en los ranchos de "Las Amazonas" del municipio de Villaflores, Chiapas, localizado en las coordenadas geográficas $16^{\circ} 13^{\prime} 57^{\prime \prime} \mathrm{N}$, $93^{\circ} 15^{\prime} 57^{\prime \prime O}$ y "Monte Calvario" del municipio de La Trinitaria, Chiapas, localizado en las coordenadas geográficas $16^{\circ} 7^{\prime} 13^{\prime \prime} \mathrm{N}, 92^{\circ} 2^{\prime} 27^{\prime \prime} \mathrm{O}$. La identificación de bacterias, así como su caracterización molecular, se realizó en el Laboratorio de Biología Molecular de la Facultad de Medicina Veterinaria y Zootecnia (FMVz) de la Universidad Autónoma de Chiapas (UNACH).

Se utilizó un muestreo aleatorio sin reemplazo, seleccionando $30 \%$ de la población total de aves en ambos ranchos. Se tomaron muestras por hisopado cloacal de las guineas con apoyo del medio Stuart, posteriormente se colocaron bajo refrigeración a una temperatura de $4^{\circ} \mathrm{C}$ hasta su procesamiento. Las muestras se inocularon en cajas de Petri con los medios agar Salmonella Shigella (MCD Lab®) y Eosiona Azul de Metileno (MCD Lab ${ }^{\circledR}$ ) para la identificación de Salmonella spp. y Escherichia coli respectivamente. Posteriormente se incubaron a $37^{\circ} \mathrm{C}$ durante $24 \mathrm{~h}$; transcurrido este periodo, se realizó la identificación de las bacterias, siendo positivas para Escherichia coli cuando las colonias tomaban una coloración verde fosforescente y para Salmonella spp., cuando las colonias presentaban centros de coloración obscura. Consecutivamente se realizó una resiembra bacteriana, incubando las muestras a una temperatura de $37^{\circ} \mathrm{C}$ durante $24 \mathrm{~h}$, con la finalidad de aislar las colonias positivas, posteriormente se trataron con un caldo de Infusión Cerebro Corazón ( $\mathrm{MCD}$ Lab ${ }^{\circledR}$ ), para evitar la muerte de las colonias dentro del medio agar, posteriormente se homogenizaron con un agitador tipo Vórtex y se incubaron a $37^{\circ} \mathrm{C}$ durante $24 \mathrm{~h}$, posterior al tiempo transcurrido, se observó en las muestras una coloración turbia indicando que las colonias crecieron en el caldo; posteriormente, las muestras se inocularon en agar Muller Hinton (MCD Lab ${ }^{\circledR}$ ) y se incubaron a $37^{\circ} \mathrm{C}$ durante $24 \mathrm{~h}$. Consecutivamente, las muestras se conservaron con glicerol y se llevaron a una temperatura de $-26^{\circ} \mathrm{C}$.

Posteriormente, se realizó el proceso de extracción de ADN siguiendo la metodología utilizada por Leotta, et al. (2005), donde en agua destilada estéril se colocó una pequeña colonia bacteriana, las muestras se homogenizaron y se trasladaron a una incubadora de baño seco (Thermo Shaker ${ }^{\circledR}$ TSI-100, 
USA) a una temperatura de $100^{\circ} \mathrm{C}$ durante $15 \mathrm{~min}$. con $600 \mathrm{rpm}$; posteriormente, las muestras se centrifugaron con una centrífuga (VelaQuin ${ }^{\circledR}$ VE-4000, México) a 1500 rpm durante 5 min., posteriormente, se extrajo el sobrenadante y se analizó la cantidad de ADN en un espectrofotómetro nanodrop (Thermo Scientific ${ }^{\circ}$, ND-ONE-W, USA).

Para la identificación del gen $r f b \mathrm{O} 157$ de Escherichia coli, se utilizó la técnica de reacción en cadena de la polimerasa (PCR punto final), colocando en tubos para microcentrífuga, $6.5 \mu \mathrm{L}$ de agua estéril, $2.5 \mu \mathrm{L}$ del primer forward, $2.5 \mu \mathrm{L}$ del primer reverse (utilizando las secuencias de nucleótidos descrita por Leotta, et al., 2005 que se muestran en la tabla 1), 12.5 $\mu \mathrm{L}$ de solución premezclada con Taq ADN polimerasa, dNTP, $\mathrm{MgCl} 2$ y tampones de reacción (GoTaq ${ }^{\circledR}$ Master Mix) y $1 \mu \mathrm{L}$ de ADN por muestra; las muestras se colocaron en un termociclador (Bio $\operatorname{Rad}{ }^{\circledR} \mathrm{C}-1000$, USA) bajo los siguientes ciclos: $94^{\circ} \mathrm{C}$ durante $5 \mathrm{~min}, 30$ ciclos a $94^{\circ} \mathrm{C}$ durante $30 \mathrm{~s}, 52^{\circ} \mathrm{C}$ durante 30 $\mathrm{s}, 72^{\circ} \mathrm{C}$ durante $1 \mathrm{~min}$, con un volumen total de $25 \mu \mathrm{L}$ a $105^{\circ} \mathrm{C}$.

\section{Tabla 1}

Características del gen rfbO157 utilizado en el estudio (Leotta, et al., 2005)

\begin{tabular}{ccc}
\hline Gen & Secuencia $\left(5^{\prime}-3^{\prime}\right)$ & Tamaño $(\mathbf{P b})$ \\
O157a & CGGACATCC ATGTGATATGG & 259 \\
O157b & TTGCCTATGTACAGCTAATCC & $25.62 \%$ \\
\hline
\end{tabular}

*Pb: Pares de bases

\section{Fuente: elaboración propia}

La detección de las bandas fue mediante gel de agarosa al 2\% teñido con bromuro de etidio, colocándose en cada pozo $1 \mu \mathrm{L}$ de azul de bromofenol y $4 \mu \mathrm{L}$ de ADN, además de colocar en el primer y segundo pozo la referencia positiva y negativa del gen respectivamente; la cámara de electroforesis se programó a $60 \mathrm{~V}$ durante $45 \mathrm{~min}$. La visualización de los resultados de electroforesis (Figura 1) se realizó con luz UV en un transiluminador (Bio Rad ${ }^{\circledR}$ Chemi-Doc XRS+, USA). 


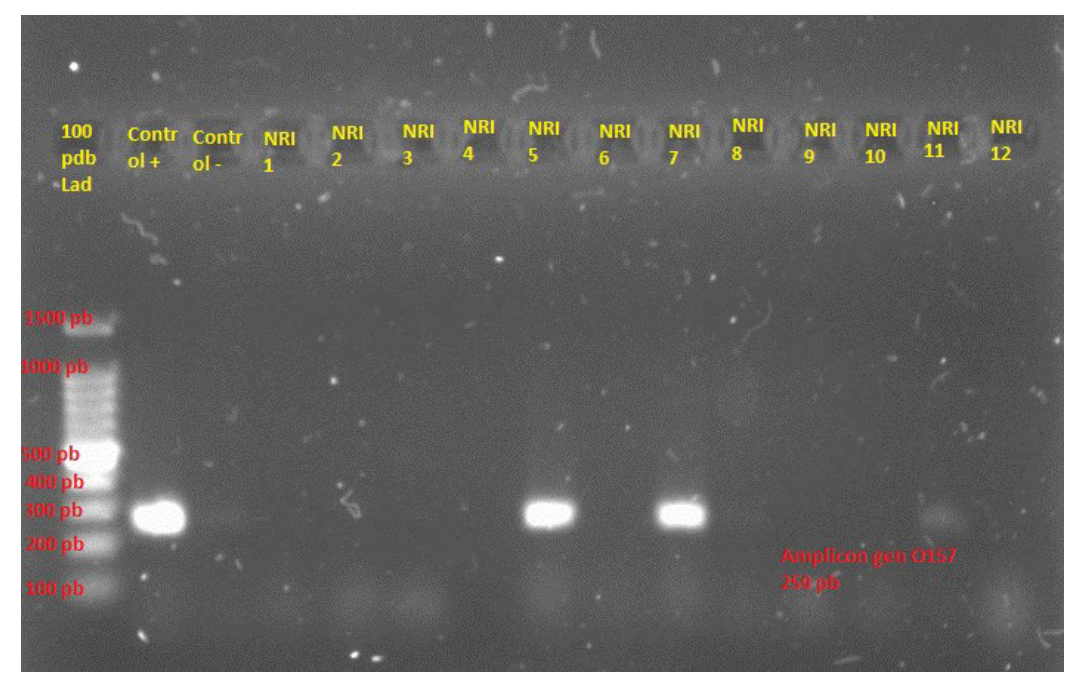

*pb/pdb: Pares de bases; NRI: aislado relacionado a Numida (por sus siglas en inglés)

Figura 1. Electroforesis en gel de agarosa de los productos de amplificación del gen rfbO157 en gallinas de Guinea. Las bandas iluminadas indican presencia del gen. Fuente: elaboración propia

Los datos se analizaron mediante fórmula de prevalencia puntual (Rodríguez-Hernández, 2015), como se muestra a continuación:

$$
\text { Prevalencia puntual }=\mathrm{Ct} / \mathrm{Nt}
$$

Donde:

Ct: Número de casos existentes (prevalente) en un momento o edad determinados.

Nt: Número total de individuos en la población en ese momento o edad determinados.

\section{RESULTADOS Y DISCUSIÓN}

No se encontró prevalencia de Salmonella spp. en ninguno de los ranchos estudiados, resultados similares a los de García, et al. (2009), quienes realizaron un estudio en España con gallinas ponedoras, encontrando una prevalencia de $1.3 \%$ de Salmonella spp. en heces colectadas mediante hisopado cloacal; esto demuestra que la prevalencia de Salmonella es baja en este tipo de método de muestreo; sin embargo, estos resultados difieren a los obtenidos por Castañeda-Salazar, et al. (2018), quienes encontraron en pollos destinados para consumo humano en Colombia una prevalencia de $29.2 \%$.

En el caso de Escherichia coli, no se encontró prevalencia en el rancho "Monte Calvario" de La Trinitaria, mientras que en el rancho "Las Amazonas" de Villaflores, el 95\% de las muestras fueron positivas (Figura 2), esto se atribuye al tipo de manejo empleado con las guineas y a la variación de 
temperaturas entre los municipios, hallazgos de Hernández-Fillor, et al. (2017), quienes realizaron un estudio en Cuba con gallinas ponedoras y encontraron una prevalencia del $45.9 \%$ que difieren con este estudio; por otra parte, Gibert-Perelló, en 2010, encontró una prevalencia de 72.7\% en muestras de distintos órganos provenientes de gallinas ponedoras en España. Sin embargo, para la identificación del serotipo O157:H7 (productor de toxina Shiga), se encontró el 10\% de prevalencia (Figura 3), esto difiere con los hallazgos de Zotta, et al. (2016), quienes no reportaron presencia del gen en vísceras de pollos en Argentina; un estudio realizado por Rípodas-Navarro, et al. (2017), encontró el 12.12\% de presencia del gen en carnes y sus derivados de especies domésticas de abasto en Madrid, España.

Estudios han demostrado la capacidad de Escherichia coli O157:H7 de colonizar la mucosa intestinal de gallinas y diseminarse al ambiente (Best, et al., 2005; La Ragione, et al., 2005), lo cual puede explicar que las gallinas y las guineas pueden actuar como portadoras de Escherichia coli O157:H7, siendo una posible amenaza a la salud pública.

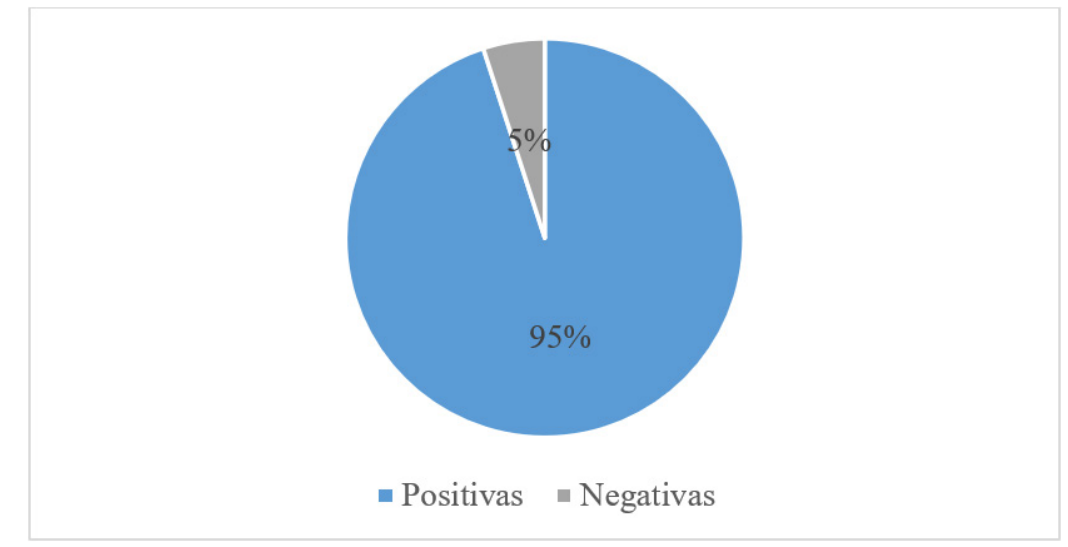

Figura 2. Prevalencia de Escherichia coli en gallinas de Guinea en del rancho "Las Amazonas", Villaflores, Chiapas. Fuente: elaboración propia

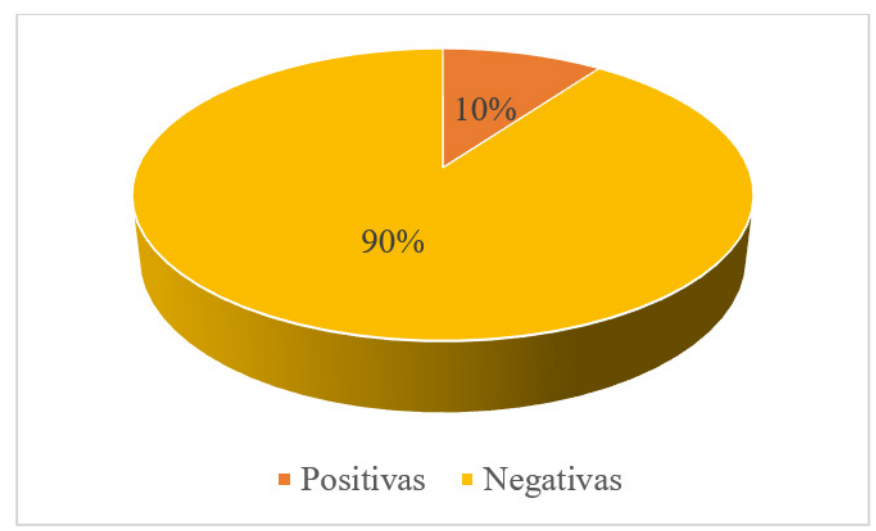

Figura 3. Prevalencia de Escherichia coli serotipo O157:H7 (productora de toxina Shiga) en gallinas de Guinea del rancho "Las Amazonas", Villaflores, Chiapas. Fuente: elaboración propia 


\section{CONCLUSIÓN}

La crianza de gallinas de Guinea representa una alternativa para productores de traspatio debido a la fácil adaptación al medio, así como la poca inversión inicial, además de presentar una fuente para la obtención de proteína de origen animal.

Si bien no se encontró prevalencia de Salmonella spp. en guineas, el estudio demuestra que las gallinas de guinea son portadoras de Escherichia coli $\mathrm{O}_{157: \mathrm{H} 7}$, por lo que es preciso seguir con estudios del impacto del serotipo en la sanidad animal, así como en la salud pública. 


\section{REFERENCIAS}

Araujo- Guerra, A., Fragozzo-Castilla, P., Orlando-Pineda, Á., MejíaArbeláez, J. y Peña-Güillen, A. (2019). Detección de Enterobacteriaceae y Hongos en huevos frescos de gallina para el consumo humano en la Ciudad de Valledupar, Cesar. Colombia. Vet. Arg. 36(373). IssN 1852-317X.

Bello- Pérez, L. A., Ortiz-Dillanes, D. M., Pérez-Memije, E., Castro-Domínguez, V. (1990). Salmonella en carnes crudas: Un estudio en localidades del estado de Guerrero. Salud pública Mex. 32,74-79.

Best, A., La Ragione, R., Sayers, A. y Woodward, M. (2005). Role for flagella but not intimin in the persistent infection of the gastointestinal tissues of specific pathogen free chicks by Shiga toxin negative Escherichia coli O157:H7. Infection and immunity, 73:1836-1846.

Camas- Robles, G.G., Ruíz-Sesma, B., Cigarroa-Vázquez, F.A. y Mendoza-Nazar, P. (2017). Caracterización de la producción intensiva de gallina guinea (Numida meleagris). Revista Mexicana de Agroecosistemas, 4(2), 104-108.

Castañeda- Salazar, R., Pereira-Bazurdo, A.N., Pulido-Villamarín, A.P., Mendoza-Gómez, M.F. (2018). Estimación de la prevalencia de Salmonella spp. en pechugas de pollo para consumo humano provenientes de cuatro localidades de Bogotá-Colombia. Infectio 23(1), 27-32.

García, C., Catalá-Gregorio, P., Soriano, J.M., Tudón, A.L., Benítez, V., Andreu, L. y Granero, I. (2009). Salmonella spp. en hisopos cloacales, heces $y$ huevos de gallinas ponedoras: Estudio preliminar. XLVI Symposium científico de avicultura,191-199.

Gibert- Perelló, M. (2010). Detección y caracterización de aislados de Escherichia coli de origen clínico y fecal en gallinas ponedoras. (Tesis doctoral, Universidad Complutense de Madrid). https://www.visavet.es/data/ tesis/deteccion-y-caracterizacion-de-aislados-de\%20Escherichia-coli-deorigen-clinico-y-fecal-en\%2ogallinas-ponedoras.pdf

Gómez- de Silva, H., Oliveras-de Ita, A. y Medellín-Legorreta, R.A. (2005). Numida meleagris. Vertebrados superiores exóticos en México: diversidad, distribución y efectos potenciales. Instituto de Ecología, Universidad Nacional Autónoma de México. Bases de datos Snib-Conabio. Proyecto Uo2o. México. D.F.

Hernández- Fillor, R.E., Báez-Arias, M., Alfonso-Zamora, P. y Espinosa-Castaño, I. (2017). Susceptibilidad antimicrobiana y formación de biopelícula en aislados de Escherichia coli procedentes de gallinas ponedoras. Rev. Salud Anim, 39(3),1-13.

La Ragione, R., Best, A., Sprigings, K., Liebana, E., Woodward, G., Sayers, A. y Woodward, M.J. (2005). Variable and strain dependent colonosation of chickens by Escherichia coli O157. Veterinary microbiology, 107:103-113. 
Leotta, I., Chinen, S., Epszteyn, E., Miliwebsky, I., Melamed, M., Motter, M. (2005). Validación de una técnica de PCR múltiple para la detección de Escherichia coli productor de toxina shiga. Rev Argent Microbiol 37(1), 1-10.

Mussaret, Z., López-Macías, C., Calva, E. (2006). Estudios mexicanos sobre Salmonella: epidemiología, vacunas y biología molecular. Revista Latinoamericana de microbiología, 48(2), 121-125.

Ochoa, T.J., Salazar-Lindo, E., Cleary, T.G. (2004). Evaluation of children with persistent infectious diarrhea. Semin Pediatr Infect Dis, 15(4), 229-36.

Rincón- Acero, D.P., Ramírez-Rueda, R.Y. y Vargas-Medina, J.C. (2011). Transmisión de Salmonella entérica a través de huevos de gallina y su importancia en salud pública. Salud UIS, 43(2), 167-177.

Rípodas- Navarro, A., Fernández-Moreira, D. y Macho-Martínez, M. (2017). Investigación de Escherichia coli productor de toxinas Shiga (sTEC) en carnes y derivados cárnicos. Sanidad mil, 73(3), 147-152

Rodríguez- Hernández, R. (2015). Prevalencia y caracterización molecular de Salmonella spp, en granjas avícolas de postura comercial en el departamento del Tolima. (Tesis de Maestría, Universidad de Tolima). http:// repository.ut.edu.co/bitstream/o01/1690/1/PREVALENCIA\%20 Y\%20CARACTERIZACI\%c3\%93N\%20MOLECULAR\%20 DE\%20SALMONELLA\%20SPP\%2c\%20EN\%20GRANJAS\%20 AV\%с3\%8dCOLAS\%20DE\%20POSTURA\%20COMERCI.pdf

Salgado, E.R., Rojas, F.P., Martínez, N., Fernández, M.S. y de la Vega, D.M. (2011). Producción extensiva de" pintadas" o gallinas de Guinea en Extremadura. Selecciones Avícolas, 53(3), 61-64.

Secretaría de Medio Ambiente y Recursos Naturales. (2000). Base de datos electrónica del Sistema de Unidades de Manejo, Conservación y Aprovechamiento de la Vida Silvestre UMA. Reporte interno de la Dirección General de Vida Silvestre, Semarnat. México, D.F.

Zaldívar- Pedroso, I.J. (2007). Manual de avicultura. II Edición. SocPA.

Zotta, C.M., Lavayén, S., Nario, F., Piquín, A. (2016). Detección de Escherichia coli en vísceras de animales bovinos y pollos destinadas para el consumo humano. J. Selva Andina Res. Soc., 7(1), 2-9. 